\title{
The Dynamics of an Extreme Precipitation Event in Northeastern Vietnam in 2015 and Its Predictability in the ECMWF Ensemble Prediction System
}

\author{
RODERICK VAN DER LINDEN \\ Institute for Geophysics and Meteorology, University of Cologne, Cologne, Germany \\ ANDREAS H. FINK \\ Institute of Meteorology and Climate Research, Karlsruhe Institute of Technology, Karlsruhe, Germany \\ JOAQUIM G. PINTO \\ Department of Meteorology, University of Reading, Reading, United Kingdom, and Institute of Meteorology and \\ Climate Research, Karlsruhe Institute of Technology, Karlsruhe, Germany \\ TAN PHAN-VAN \\ Department of Meteorology and Climate Change, Vietnam National University, Hanoi University \\ of Science, Hanoi, Vietnam
}

(Manuscript received 2 August 2016, in final form 3 March 2017)

\begin{abstract}
A record-breaking rainfall event occurred in northeastern Vietnam in late July-early August 2015. The coastal region in Quang Ninh Province was hit severely, with station rainfall sums in the range of 1000$1500 \mathrm{~mm}$. The heavy rainfall led to flooding and landslides, which resulted in an estimated economic loss of \$108 million (U.S. dollars) and 32 fatalities. Using a multitude of data sources and ECMWF ensemble forecasts, the synoptic-dynamic development and practical predictability of the event is investigated in detail for the 4-day period from 1200 UTC 25 July to 1200 UTC 29 July 2015, during which the major portion of the rainfall was observed. A slowly moving upper-level subtropical trough and the associated surface low in the northern Gulf of Tonkin promoted sustained moisture convergence and convection over northeastern Vietnam. The humidity was advected in a moisture transport band lying across the Indochina Peninsula and emanating from a tropical storm over the Bay of Bengal. Analyses of the ECMWF ensemble forecasts clearly showed a sudden emergence of the predictability of the extreme event at lead times of 3 days that was associated with the correct forecasts of the intensity and location of the subtropical trough in the 51 ensemble members. Thus, the Quang Ninh event is a good example in which the predictability of tropical convection arises from large-scale synoptic forcing; in the present case it was due to a tropical-extratropical interaction that has not been documented before for the region and season.
\end{abstract}

\section{Introduction}

In the period from 1200 UTC 25 July until 1200 UTC 3 August 2015, northeastern Vietnam was hit by an extreme precipitation event. During this period, coastal

\footnotetext{
Supplemental information related to this paper is available at the Journals Online website: http://dx.doi.org/10.1175/ WAF-D-16-0142.s1.
}

Corresponding author e-mail: Roderick van der Linden, rvdlinde@uni-koeln.de stations in Vietnam's northeastern Quang Ninh Province (Fig. 1) reported accumulated rainfall totals between about 1000 and $1500 \mathrm{~mm}$. These were the highest-ever recorded rainfall sums in this region for the abovementioned 9-day period. The exceptionality is illustrated by the fact that the observed values were partly more than fourfold as high as the observed absolute station maxima in the last 40-50 years. Not surprisingly, the extreme rainfall event led to catastrophic flooding and landslides, which resulted in 32 fatalities and an estimated economic loss of $\$ 108$ million [U.S. dollars; United Nations (2015)]. 


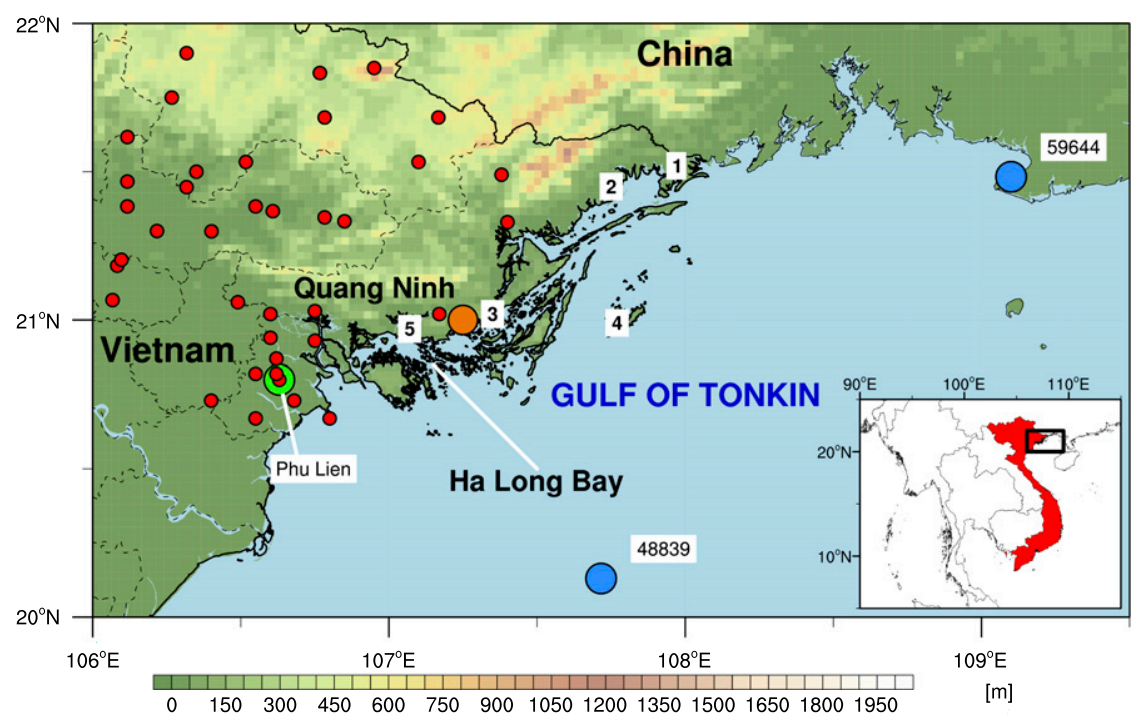

FIG. 1. Map of the study region with locations of NHMS stations (red dots and numbers). For stations 1-5 (cf. Table 1), hourly rainfall measurements are available. Vietnamese provinces are delineated with thin, dashed lines. The orange dot denotes the location of the center of the ECMWF grid box that was used in the evaluation of the ensemble forecast (cf. Fig. 11). The green dot indicates the location of the Phu Lien radar station, and the blue dots denote the locations of the Bach Long Vy (WMO station ID 48839) and Beihai (WMO station ID 59644) radiosonde stations.

According to D.-Q. Nguyen et al. (2014), northeastern Vietnam can be separated into two distinct climate zones, termed $\mathrm{N} 2$ and N3, that are characterized by a single rainy season that lasts from about May to October. The climate zones N2 and N3 correspond with the political regions "Northeast" and "Red River Delta," respectively. Monthly rainfall totals in these regions normally peak in July and August (e.g., D.-Q. Nguyen et al. 2014; Phan et al. 2009), which is partly related to the activity of the ITCZ (K. C. Nguyen et al. 2014).

Several factors that can lead to extreme rainfall in the study region during the rainy season have been documented in previous studies. The mei-yu front, along which mesoscale convective complexes form, is a synoptic feature that causes extreme rainfall in the early part of the rainy season. With the northward progression of the Southeast Asian monsoon, the mei-yu front develops in May and June (Yihui and Chan 2005; Xu et al. 2009). Although the mei-yu front mainly affects a region from southeastern China, across Taiwan, and farther northeastward to the East China Sea, northeastern Vietnam is also frequently affected by the rainbands that are associated with this front (Xu et al. 2009). The South China Sea usually is the main moisture source, but sometimes moisture is also transported from the Bay of Bengal to the mei-yu front (American Meteorological Society 2016). Other synoptic systems affecting the study region with copious rains are tropical cyclones
(TCs) that originate in the northwest Pacific and enter the South China Sea. Although the TC season peaks in August in the northwest Pacific region and accounts for $11 \%-15 \%$ of the total monthly rainfall across this region in July and August (Jiang and Zipser 2010), northeastern Vietnam is climatologically not frequently affected by TCs during the peak of the rainy season. This could be attributed to recurving TC tracks and to a strong wind shear over the Gulf of Tonkin, which inhibits TC genesis. Nguyen-Thi et al. (2012) also found that total rainfall in northeastern Vietnam (Mong Cai station) is not dominantly influenced by TC-related rainfall.

Previous studies put a focus on extreme events in Vietnam occurring during the transition from the rainy to the dry season in October and November (e.g., Yokoi and Matsumoto 2008; Chen et al. 2012; Wu et al. 2011; Wu et al. 2012; Van der Linden et al. 2016a). In these cases, interactions between tropical large- and synopticscale waves, the Borneo vortex, boreal fall cold surges of the northeasterlies over the South China Sea with the ITCZ, and the orography of the central Vietnamese coast caused catastrophic rainfall, reaching or exceeding the values observed in the Quang Ninh Province event. For example, in the city of Hue more than $700 \mathrm{~mm}$ of rainfall was measured in a 3-day period related to the combined influence of a tropical disturbance and the Madden-Julian oscillation (Wu et al. 2012). Among the above-cited studies, Wu et al. (2011) is the only one 
TABLE 1. Geographical information on the five stations in Quang Ninh Province (cf. Fig. 1) from which hourly rainfall measurements are available. Five-digit station ID numbers indicate a surface synoptic observation (SYNOP) station and three-digit station IDs are regional station IDs.

\begin{tabular}{cccccc}
\hline \hline No. & Station name & Station ID & Lat $\left({ }^{\circ} \mathrm{N}\right)$ & Lon $\left({ }^{\circ} \mathrm{E}\right)$ & Height $(\mathrm{m})$ \\
\hline 1 & Mong Cai & 48838 & 21.52 & 107.97 & 7 \\
2 & Quang Ha & 097 & 21.45 & 107.75 & 10 \\
3 & Cua Ong & 094 & 21.02 & 107.35 & 60 \\
4 & Co To & 093 & 20.98 & 107.77 & 70 \\
5 & Bai Chay & 092 & 20.97 & 107.07 & 87 \\
\hline
\end{tabular}

describing an extreme rainfall event near our study region in the Red River Delta. It affected the vicinity of Vietnam's capital Hanoi during October-November 2008, when more than $800 \mathrm{~mm}$ of rainfall was measured in only 3 days. The event was caused by the combined influence of a tropical disturbance, which had formed over the South China Sea, and a strong northeasterly monsoonal flow. Wu et al. (2011) argue that the interplay between the disturbance and the monsoonal flow resulted in a strong convergence of low-level winds over northern Vietnam and caused the extreme event.

The extreme precipitation event in northeastern Vietnam in late July-early August 2015 could not be assigned to any of the above-described processes. It was not associated with a TC, and the other processes occur during other seasons of the year or across other regions of Vietnam. As a consequence, the first major aim of this study is to disentangle the synoptic-dynamic causes of this extreme precipitation event. The second major goal is to study the practical predictability of the event using the European Centre for Medium-Range Weather Forecasts (ECMWF) ensemble forecast system. It is known from other monsoon systems that the predictability of day-to-day variations of tropical rainfall is low as a result of the chaotic nature of convection, sometimes barely exceeding forecasts based on climatology (e.g., Lafore et al. 2017; Milton et al. 2017). Thus, not surprisingly, the severity of the event and particularly the location of the maximum rainfall were not well forecasted by the national numerical weather prediction system of Vietnam's National Center for Hydrometeorological Forecasting (Du Duc et al. 2016). However, even though convective activity is highly stochastic, synoptic controls on convection can cause predictability (Söhne et al. 2008; Lafore et al. 2017). It will be shown in the present study that the Quang Ninh extreme event is a salient example in which the correct ensemble prediction of a subtropical trough about 3 days before the event significantly raised the predictability of the tropical monsoon convection. This predictability would have been sufficient in skill and lead time to ensure that protection measures could be taken and warnings could be timely issued (Jones and Golding 2014).

The data used for the analysis are described in section 2 . To achieve the above-mentioned two major goals, the results section was divided into three parts. Section 3 discusses the spatiotemporal characteristics of the rainfall event, which is followed by an in-depth analysis of the dynamical causes of the event in section 4 . The practical predictability is studied in section 5 using 51 members of the ECMWF Ensemble Prediction System (EPS) at forecast lead times up to 10 days. Finally, section 6 provides a summary and discussion of the results.

\section{Data and methods}

The present study took advantage of a multitude of data sources. The in situ evolution of the extreme event was analyzed using station measurements provided by the Vietnamese National Hydrometeorological Service (NHMS; NHMS 2015, unpublished data). Precipitation measurements were provided at daily resolution (12001200 UTC, i.e., 1900-1900 LT) for 44 stations that are located in Quang Ninh Province and the adjacent area (Fig. 1). NHMS also provided hourly rainfall measurements for four coastal and one island station in Quang Ninh Province (Fig. 1 and Table 1). For a classification of the event in terms of its statistical extraordinariness, historical daily time series for these five stations were available from the NHMS database; data availability at the individual stations during the period 1960-2012 ranges between 23 and $53 \mathrm{yr}$ (cf. the $x$ axis labels in Fig. 2). Further data provided from NHMS were daily 1200 UTC radiosonde profiles from Bach Long Vy Island located in the center of the Gulf of Tonkin (Fig. 1) for the period 25-28 July 2015. The latter were complemented by upper-air data from Beihai (China) along the northern coast of the Gulf of Tonkin (cf. Fig. 1) taken from the Integrated Global Radiosonde Archive (IGRA; Durre et al. 2006).

To diagnose the larger-scale evolution of deep convection and rainfall, two gridded satellite products and one gridded surface radar product were utilized. To assess the precipitation in nongauged areas and over the waters of the Gulf of Tonkin, the recently released satellite-based NASA Global Precipitation Measurement (GPM) Integrated Multisatellite Retrievals for GPM (IMERG) product (Huffman et al. 2015), which is the successor to NASA's Tropical Rainfall Measurement Mission (TRMM) 3B42 product (Huffman et al. 2007), was employed. NASA GPM IMERG data are available at $0.1^{\circ} \times 0.1^{\circ}$ latitude-longitude and 30-min resolution, but were accumulated to daily values to match the accumulation period of the daily station data. 


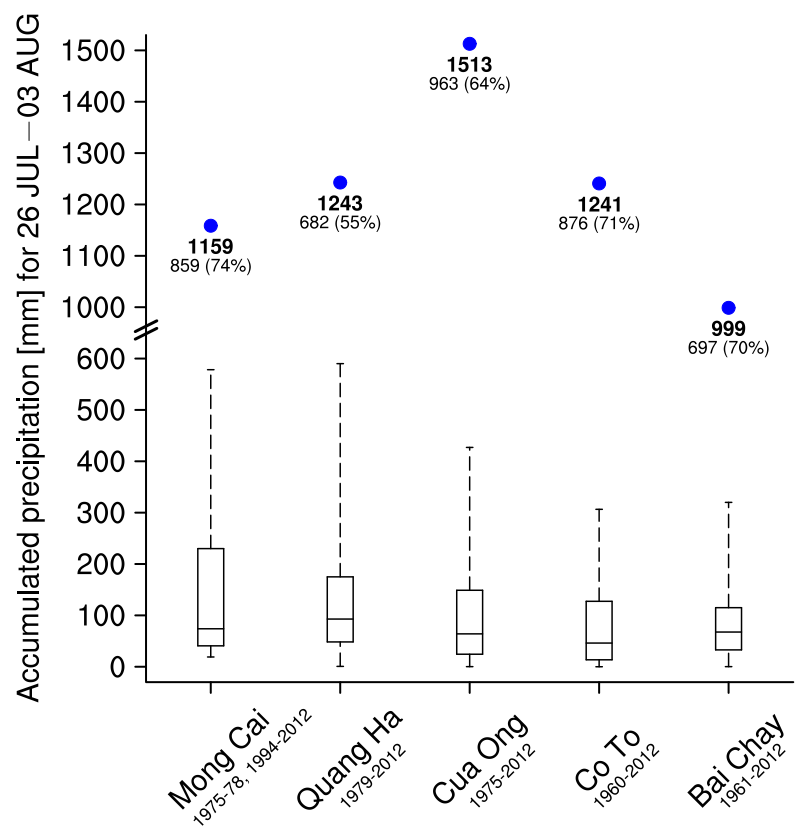

FIG. 2. Box-and-whisker plots of accumulated rainfall (mm) during 1200 UTC 25 Jul-1200 UTC 3 Aug. The availability of historical data is indicated below the station names. The blue dots and the large boldface numbers below the blue dots indicate the accumulated rainfall $(\mathrm{mm})$ during the same period in 2015 and the smaller numbers indicate the accumulated rainfall $(\mathrm{mm})$ during the period 1200 UTC 25 Jul-1200 UTC 29 Jul 2015. The percentage of rainfall during the shorter period relative to the whole period is indicated by the percentages in parentheses.

The few available validation studies of the NASA GPM IMERG product suggest at least the same performance as the NASA TRMM 3B42 version 7 product (e.g., Guo et al. 2016; Prakash et al. 2017). Measurements from the geostationary Multifunctional Transport Satellite-2 (MTSAT-2), which is operated by the Japan Meteorological Agency, were used to identify deep convection. Particularly, brightness temperatures at 0000 and 1200 UTC from the $10.8-\mu \mathrm{m}$ MTSAT-2 infrared channel that are available in $0.04^{\circ} \times 0.04^{\circ}$ latitude-longitude and 30-min resolution were utilized here. Finally, radar reflectivity data from the C-band precipitation radar in Phu Lien at 5-min resolution were available for the period 25-28 July 2015 (cf. Fig. 1; NHMS 2015, unpublished data).

For a description of the dynamical causes and the practical predictability of the extreme precipitation event, various ECMWF products were downloaded from the ECMWF archive. The horizontal wind and its divergence, geopotential height, temperature, specific humidity, and potential vorticity were taken from 0000 and 1200 UTC ECMWF operational analyses at 13 pressure levels between 1000 and $200 \mathrm{hPa}$ at $0.125^{\circ} \times$ $0.125^{\circ}$ latitude-longitude resolution. Additionally, mean sea level pressure data from this analysis were employed. Sea surface temperatures (SSTs) during the extreme event were analyzed using the daily, $0.25^{\circ} \times$ $0.25^{\circ}$ NOAA Optimum Interpolation SST version 2 high-resolution dataset (Reynolds et al. 2007). To assess the exceptionality of the total column water content during the event with respect to the period 1986-2015, the ECMWF ERA-Interim reanalysis was used at $0.75^{\circ} \times 0.75^{\circ}$ latitude-longitude resolution (Dee et al. 2011). Daily accumulated surface evaporation was retrieved from the same reanalysis.

Precipitation, mean sea level pressure, and $200-\mathrm{hPa}$ geopotential height fields at $0.25^{\circ} \times 0.25^{\circ}$ latitudelongitude resolution from the control and 50 perturbed forecasts of the ECMWF EPS system were retrieved at lead times of 240, 168, 144, 120, 96, 72, 48, and $24 \mathrm{~h}$. From the EPS data archive, gridded fields of the extreme forecast (EFI) and the shift of tails (SOT) indices as well as quantiles of the model climatology for 24-h precipitation totals were downloaded. The underlying model climatology, necessary to calculate the three parameters for various forecast lead times, is computed with the ECMWF model cycle 41r1 for the previous $20 \mathrm{yr}$, but forecasts with 11 members start only every Monday and Thursday (ECMWF 2015). For a given date, the model climatology is based on 1980 values, that is, $20 \mathrm{yr} \times 11$ members $\times 9$ start dates centered on the week of interest (ECMWF 2015). These three variables allow for a probabilistic, space- and time-dependent practical predictability assessment of the extreme event with respect to the model climate (Zsótér 2006; cf. section 5). First note that EFI and SOT are integral measures to assess the likelihood of an extreme event, but the information on the underlying statistical moments of the probability density function (PDFs) are lost. Thus, we have also calculated the PDFs and cumulative distribution functions (CDFs) at grid points using the quantiles. Second, the term practical predictability is used here to avoid confusion with "intrinsic predictability," the latter referring to regime-dependent theoretical limits of predictability, which is not studied here.

The operational analyses were used to calculate vertically integrated moisture flux vectors (cf. Peixoto and Oort 1992) between the surface pressure and the 300-hPa pressure level. The use of surface pressure ensures the corrections for orography and moisture flux convergence were computed using a centered finitedifference approach. The vertically averaged potential vorticity between the 500 - and $200-\mathrm{hPa}$ pressure levels was determined from the operational analysis as in Fröhlich and Knippertz (2008). The 200-hPa trough axes were calculated from the operational analysis and EPS 


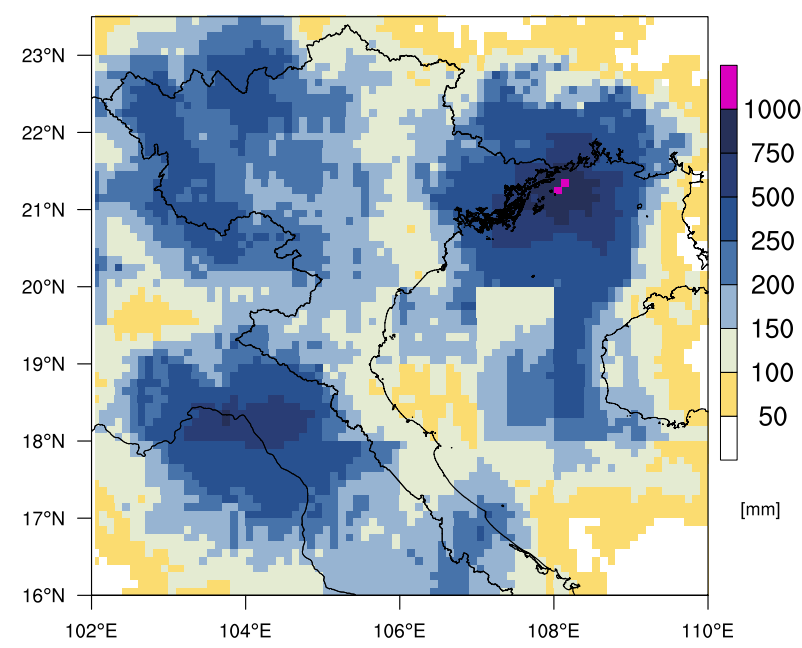

FIG. 3. NASA GPM IMERG accumulated rainfall (mm) during 1200 UTC 25 Jul-1200 UTC 3 Aug 2015.

forecasts using zonal geopotential gradients at $200 \mathrm{hPa}$ as in Knippertz (2004).

\section{Description of the extreme precipitation event}

Between 1200 UTC 25 July and 1200 UTC 3 August 2015, record-breaking rainfall was observed along the northeastern Vietnamese coast between Ha Long Bay and the border region of Vietnam with China. At five stations in northeastern Vietnam, rainfall sums ranging between 1000 and $1500 \mathrm{~mm}$ were recorded during this period (Fig. 2). Based on the NASA GPM IMERG satellite product, the highest rainfall sums occurred over the Gulf of Tonkin, peaking at over $1000 \mathrm{~mm}$ (Fig. 3), but rainfall sums over northeastern Vietnam, comprising mainly Quang Ninh Province, still reached between 750 and $1000 \mathrm{~mm}$. During this period, other rainfall maxima occurred over Laos on the windward (i.e., westward) side of the Annamese Cordillera and in northwestern Vietnam. The five stations along the coast in northeastern Vietnam and on Co To Island in the Gulf of Tonkin (cf. Fig. 1 and Table 1), for which hourly rainfall measurements were available, reported rainfall totals very close to or above $1000 \mathrm{~mm}$ (Figs. 2 and 4a). The period 1200 UTC 25 July-1200 UTC 3 August 2015 can be subjectively divided into two periods: one period with heavy and persistent rainfall over the Gulf of Tonkin, southeastern China, and northeastern Vietnam from 1200 UTC 25 July until 1200 UTC 29 July 2015 (Figs. 4b and 5) and another period from 1200 UTC 29 July until 1200 UTC 3 August 2015 with rather regional convection (cf. Fig. 5) that also occurred farther inland over Vietnam (cf. Figs. 4a and 4b). The recurrent outbreaks of regional convection during the second period, which followed the
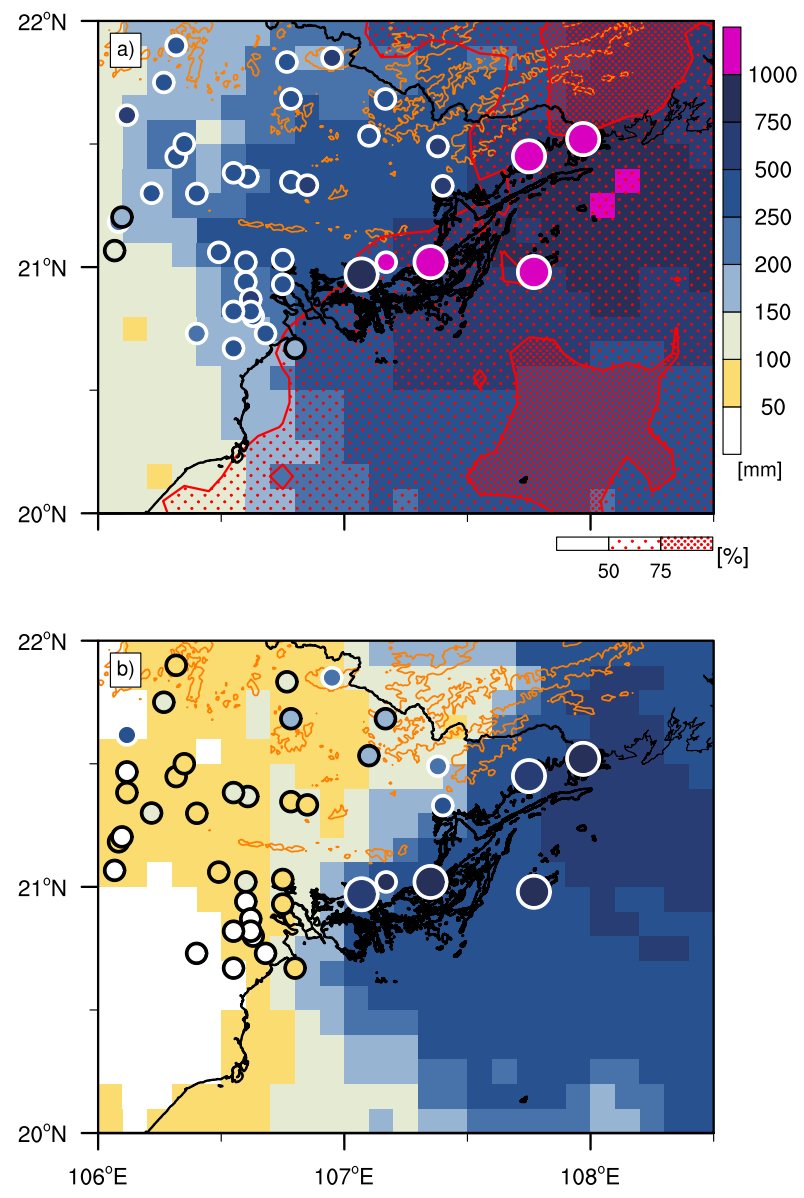

FIG. 4. NASA GPM IMERG and station rainfall in the study region for the two rainfall periods. (a) Accumulated rainfall (mm) during 1200 UTC 25 Jul-1200 UTC 3 Aug 2015 (contours and colored dots) and percentage of accumulated rainfall during 1200 UTC 25 Jul-1200 UTC 29 Jul 2015 relative to the whole period (red stippling; based on NASA GPM IMERG). (b) Accumulated rainfall (mm) during 1200 UTC 25 Jul-1200 UTC 29 Jul 2015. The thin orange lines denote the 500-m surface elevation.

diurnal cycle at some stations (e.g., Fig. 5b), were favored by high moisture, low stability, and low-level winds blowing orthogonal to coastal mountain chains (not shown). For the whole period, the observed rainfall amounts in 2015 were at least twice as large as the historical station rainfall maxima for the same period (Fig. 2). For the stations Cua Ong, Co To, and Bai Chay, they even reached 3-4 times the climatological maxima within their respective observation periods given in Fig. 2. Overall, the climatological median and maximum rainfall amounts are higher at the two stations in the north when compared with the other stations farther south (Fig. 2), which means that the statistical extraordinariness of the event is even greater at the stations farther south.

During the first period, which is indicated by the gray vertical dashed lines in Fig. 5, more than 50\% of the total 

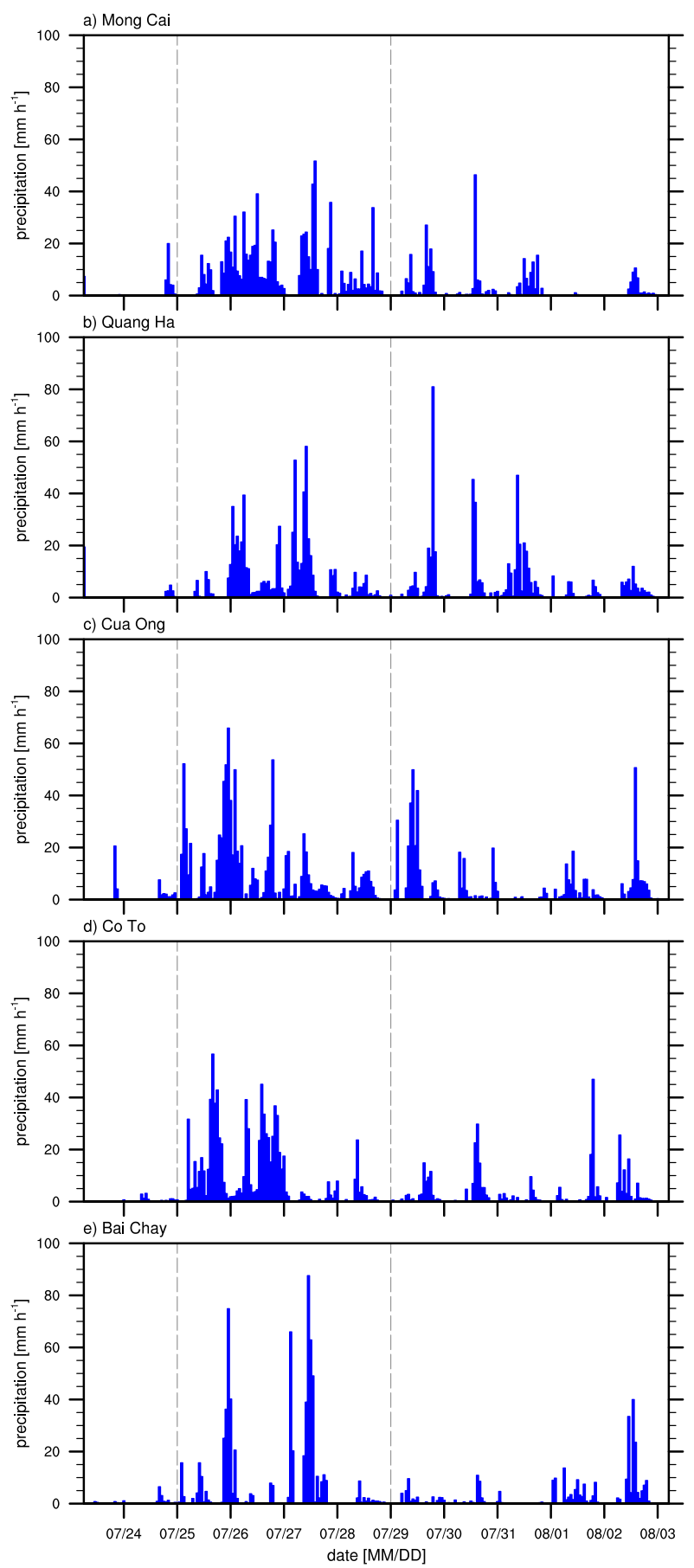

FIG. 5. Hourly rainfall at the five NHMS stations in Quang Ninh Province (cf. Fig. 1 and Table 1). The dashed vertical lines define the period from 1200 UTC 25 Jul to 1200 UTC 29 Jul 2015.

rainfall during the heavy precipitation event was observed (Figs. 2 and 4a), which corresponds to 682$963 \mathrm{~mm}$ (about $55 \%-74 \%$ of rainfall during the whole period) at the five stations (Fig. 2). During the first period, a pronounced gradient of rainfall between the
Gulf of Tonkin including coastal mainland regions and regions farther inland can be observed both in station data and satellite measurements (Fig. 4b). In contrast to other inland stations, four stations that are located in the mountainous central area north of the study region observed more than $150 \mathrm{~mm}$ rain during the first period (Fig. 4b). This obvious difference between station measurements and NASA GPM IMERG observations might be related to orographic effects, because these stations are mostly located in windward regions at higher elevations (cf. Fig. 1). Another difference is the general dry bias of NASA GPM IMERG (Fig. 4), even though closer scrutiny would need to take the inherent problems of pixel-to-gauge comparisons into account. Brightness temperatures as low as $200 \mathrm{~K}$ indicate deep convection over the Gulf of Tonkin and at the coast across northeastern Vietnam (Fig. 6). However, especially from 1200 UTC 28 July 2015 onward, convection also spread inland and affected the whole region north of Vietnam.

On an hourly basis, the maximum rainfall during the first period ranged between $51.7 \mathrm{~mm} \mathrm{~h}^{-1}$ in Mong Cai (Fig. 5a) and $87.6 \mathrm{~mm} \mathrm{~h}^{-1}$ in Bai Chay (Fig. 5e). Although the maximum hourly rainfall was observed in Bai Chay, rainfall during the first period was not as persistent as for the other stations and was considerably weaker after 0700 UTC 28 July 2015 (Fig. 5e). In Co To, the period of heavy precipitation was even shorter and ended at about 1200 UTC 27 July 2015. In the following, the focus is put on the first period because of 1) the persistence of rainfall, 2) the fact that the highest (station) rainfall amounts were almost exclusively observed in regions close to the coast, and 3) the large-scale dynamical forcing (see section 4).

\section{Synoptic-dynamic development}

Strong convection was linked to a weak surface low in the Gulf of Tonkin and northeastern Vietnam during the first period (Fig. 6). During the first period, the surface low weakened, and its center slowly moved westward from the northeastern coast to north-central Vietnam (Fig. 6). While moving slowly westward, the low was associated with low-level wind convergence (see Fig. S1 in the online supplement to this article) and destabilization of the atmosphere (not shown), thus promoting the heavy rainfall in the region under study. The formation of the cyclone and its movement was associated with a 200-hPa trough, which was located northwest of Vietnam over southern China, as indicated by the solid lines in Fig. 7. Between 1200 UTC 25 July and 1200 UTC 29 July 2015, the 200-hPa trough moved westward and gradually weakened (Fig. 7) until it was no longer 


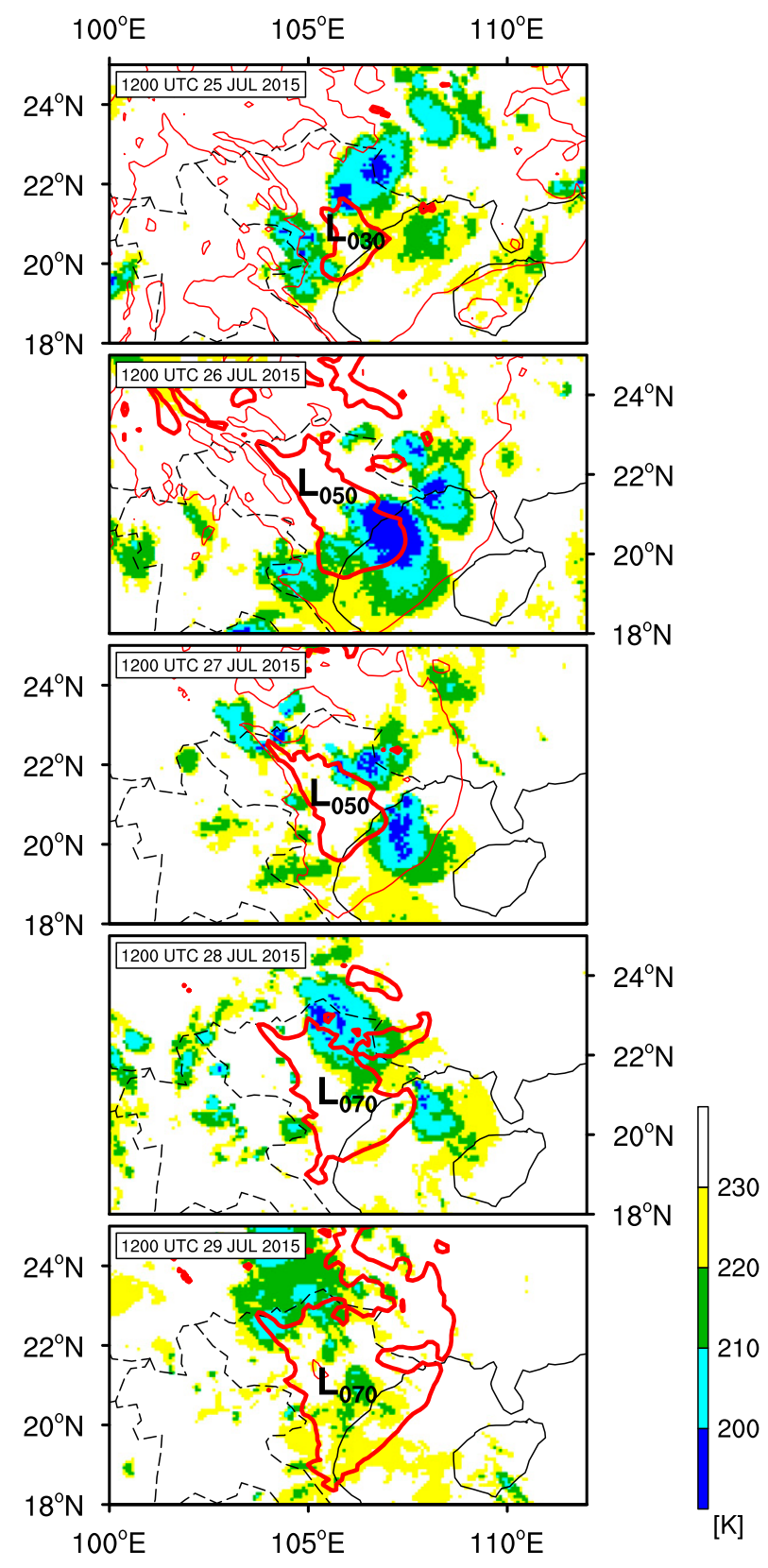

FIG. 6. MTSAT-2 brightness temperatures in the $10.8-\mu \mathrm{m}$ infrared channel (colors; K) between 1200 UTC $25 \mathrm{Jul}$ and 1200 UTC 29 Jul 2015 and the 999- to 1007-hPa ECMWF operational analysis mean sea level pressure (red contours; $\mathrm{hPa}$ ). The thick red contour lines denote the contours of the mean sea level pressure minima.

detectable after 1200 UTC 29 July 2015 (not shown). The trough was present in the mid- to upper troposphere as evidenced by the $200-500-\mathrm{hPa}$ vertically averaged potential vorticity fields; Fig. 7 shows a trough of 2 potential vorticity units (PVUs, where $1 \mathrm{PVU}=10^{-6} \mathrm{~K} \mathrm{~kg}^{-1} \mathrm{~m}^{2} \mathrm{~s}^{-1}$ ) slightly to the east of the geopotential height trough axis

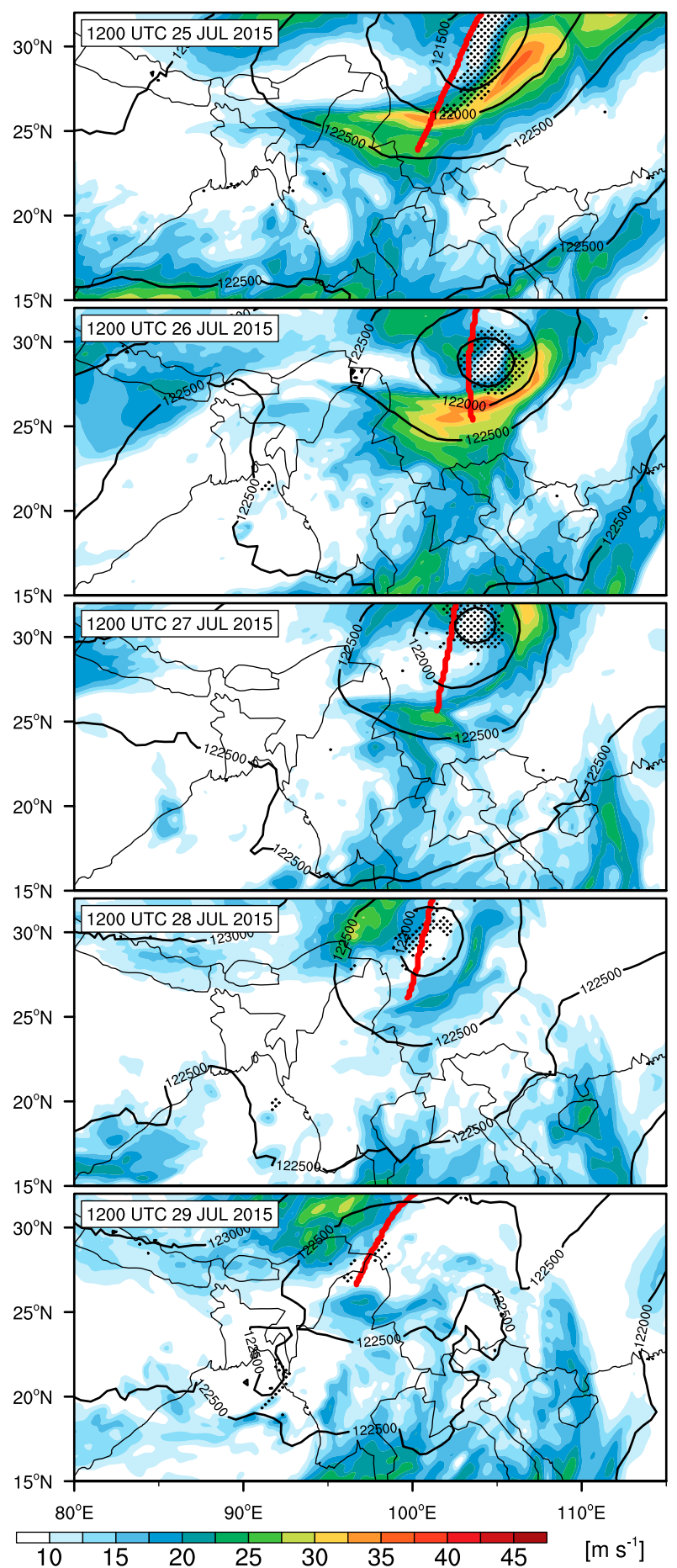

FIG. 7. ECMWF operational analysis $200-\mathrm{hPa}$ wind speed (colors), 200-hPa geopotential height (contours; $\mathrm{m}^{2} \mathrm{~s}^{-2}$ ), 200-hPa geopotential height trough axes (red lines), and 500-200-hPa 2-PVU vertically averaged potential vorticity (stippling) between 1200 UTC 25 Jul and 1200 UTC 29 Jul 2015. 
at 1200 UTC 25 July 2015 . Thereafter, areas with 2 PVU can only be detected east of the geopotential height trough axes, which are associated with an upperlevel cyclonic vortex (Fig. 7). However, the extent of the areas with 2 PVU decreased considerably in the following days (until 1200 UTC 29 July 2015; Fig. 7, bottom).

Inspection of radar loops from Phu Lien (cf. Fig. 1 for the location of the radar) revealed that the maximum radar reflectivity occurred in a band on the eastern flank of the surface low. This band was located mainly over the Ha Long Bay and the adjacent coastline (e.g., 1200 UTC 27 July 2015; Fig. S2). Along with the westward displacement of the trough, the regions of maximum rainfall moved from the Gulf of Tonkin closer to the coast (not shown). Moreover, deep convection also affected regions farther inland as a result of the westward displacement of the weakening trough, especially from 1200 UTC 28 July 2015 onward (Fig. 6). While the horizontal trough axis was tilted positively (i.e., from southwest to northeast) on 25 July 2015, it was oriented more meridionally between 26 and 28 July 2015 (Fig. 7). The 200-hPa geopotential height trough showed a positive tilt again on 29 July 2015 , although the trough was already less pronounced by this date (Fig. 7), especially when also taking the vertically averaged potential vorticity into consideration. Note that cyclogenesis over the Gulf of Tonkin was not supported by a classical "rightentrance subtropical jet region configuration" since the jet to the west of the trough was located too far northwest of the region (Fig. 7).

Moisture was transported to northeastern Vietnam across the Indochina Peninsula by a strong and persistent moisture flux between the surface and the $300-\mathrm{hPa}$ level. The transport band emerged from the southern flank of a strong monsoon depression over the northern Bay of Bengal between 1200 UTC 25 July and 1200 UTC 29 July 2015 (Fig. 8). The monsoon depression was almost stationary between 26 and 29 July 2015 and developed into the tropical storm Komen that was tracked on 30 and 31 July 2015 (WMO 2015). Note that strong vertical shear typically suppresses tropical cyclogenesis over the Bay of Bengal during this season (Yanase et al. 2012). The moisture flux was further enhanced over the South China Sea and the Gulf of Tonkin, which was possibly related to a moisture uptake over SSTs in excess of $28^{\circ} \mathrm{C}$; the surface evaporation was estimated to be in the range of 8-10 $\mathrm{mm} \mathrm{day}^{-1}$ by ERA-Interim (Fig. S3). The moisture flux contributed to high amounts of total column water (slightly more than $70 \mathrm{~mm}$ ) that corresponds to an exceedance of the 95th percentile for the 30-yr period 1986-2015 above the coast of northeastern Vietnam (Fig. S4). Above the Gulf of Tonkin, even the 98th percentile was exceeded.

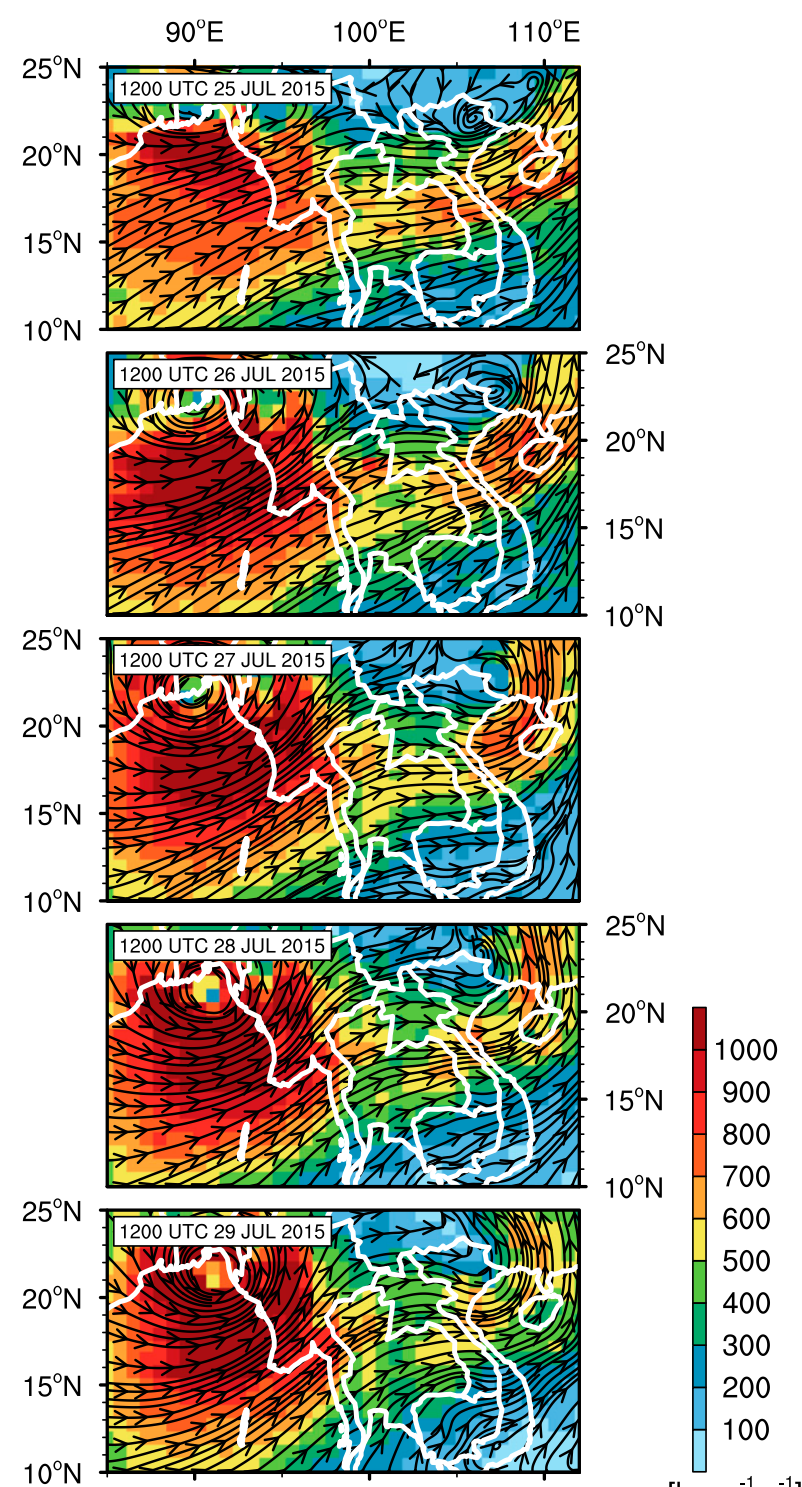

$90^{\circ} \mathrm{E}$

$100^{\circ} \mathrm{E}$

$110^{\circ} \mathrm{E}$

$\left[\mathrm{kg} \mathrm{m}^{-1} \mathrm{~s}^{-1}\right]$

FIG. 8. Surface-300-hPa vertically integrated moisture flux $\left(\mathrm{kg} \mathrm{m}^{-1} \mathrm{~s}^{-1}\right)$ between 1200 UTC $25 \mathrm{Jul}$ and 1200 UTC $29 \mathrm{Jul} 2015$ (calculations based on ECMWF operational analysis).

Associated with the westward movement of the trough, the change of the tilt of the horizontal trough axis, and the westward displacement of the surface low over northern Vietnam, tropospheric moisture flux changed from a rather zonal orientation on 1200 UTC 25 July 2015 to an increasingly meridional orientation from 1200 UTC 26 July 2015 onward (Fig. 8). Convection was most likely triggered by tropospheric moisture flux into and moisture flux convergence over the study region. Skew $T-\log p$ diagrams for Bach Long Vy Island and Beihai along the northern coast of the Gulf of Tonkin indicate lifting condensation level pressures of 

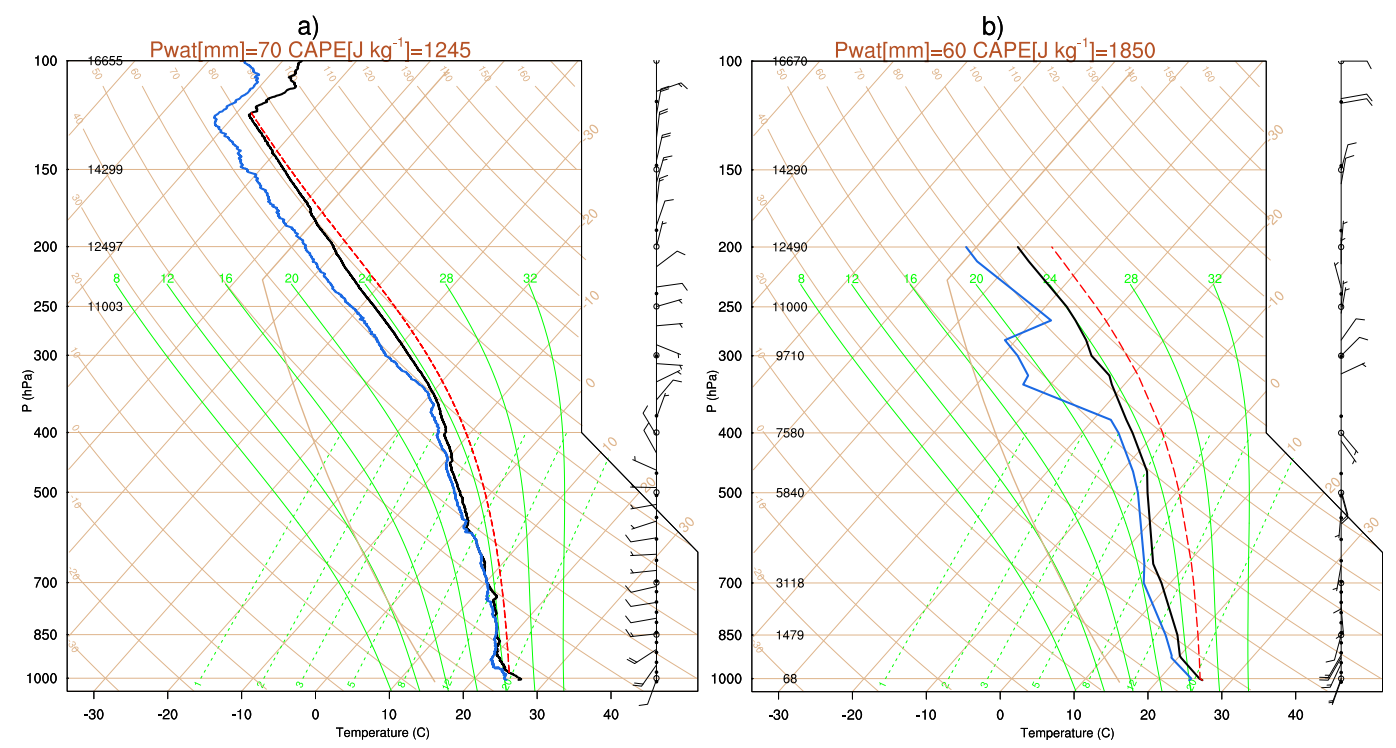

FIG. 9. Skew $T-\log p$ diagrams for (a) Bach Long Vy (WMO station ID 48839) and (b) Beihai (WMO station ID 59644) at 1200 UTC $27 \mathrm{Jul} 2015$. The values of precipitable water (Pwat; mm) and CAPE ( $\left.\mathrm{J} \mathrm{kg}^{-1}\right)$ at both locations are indicated in the headings of (a) and (b).

about $980 \mathrm{hPa}$ at 1200 UTC 27 July 2015 (Fig. 9). Thus, a lifting of near-sea surface parcels by only about 200 $300 \mathrm{~m}$ was sufficient to cause their free ascent to tropopause levels at about $125 \mathrm{hPa}$. Figure 9 also shows that the atmosphere was very moist (precipitable water values between 60 and $70 \mathrm{~mm}$ ) with only moderate convective available potential energy (CAPE) values between 1200 and $1900 \mathrm{~J} \mathrm{~kg}^{-1}$, hinting at synoptically forced convective ascent of moisture-laden air masses, but not at strong convective organization.

The moisture flux convergence was most pronounced along the coast of northeastern Vietnam and could be rather attributed to speed convergence resulting from surface friction at the coast than to directional convergence in this region (Fig. 10). Only on 27 July 2015 may the directional convergence have also played a role over the northern Gulf of Tonkin. In particular when moisture fluxes are oriented orthogonal toward the coastline, interactions with orography play a role (cf. Figs. 4 and 10). This is most pronounced in northern Quang Ninh Province and in southeastern China; the moisture flux was strongest on 26 and 27 July 2015 but it was almost parallel to the coast. On the other hand, the moisture flux vectors had substantial components orthogonal to the coastline of northeastern Vietnam on 29 July 2015.

\section{Representation in ECMWF Ensemble Prediction System forecasts}

Numerical weather and climate prediction models have considerable biases in tropical rainfall forecasts (e.g., Webster et al. 2010; Li and Robertson 2015) that are also lead time dependent. Thus, it is recommended to compare probabilistic forecasts with the lead-timedependent model climatology instead of comparing simulated precipitation amounts quantitatively with observed precipitation amounts. The underlying assumption to infer evidence of an imminent extreme rainfall event is that if the forecast is "extreme" compared with the model climatology, the observed rainfall amount shall be considered extreme when compared against the real climatology (ECMWF 2015). This approach also has advantages in that problems with rain gauge densities and errors in satellite-derived rainfall estimates are circumvented.

In other words, for the case under study it shall be evaluated at which lead times, if any, extreme 24-h precipitation totals were forecasted in the Gulf of Tonkin area with respect to the EPS model climatology. One simple evaluation approach is to plot CDFs of the model climatology and the 51 EPS members for a grid point in the target area. The ensemble forecast CDFs at a grid point near Cua Ong (cf. orange dot in Fig. 1) are plotted in Fig. 11 for the forecast verification time 0000 UTC 27 July 2015; that is, the precipitation accumulation period is the 24 -h period before this time. It is striking for this grid point that the forecasts remain close to the model climatology until $72 \mathrm{~h}$ before the event, when almost $50 \%$ of all members of the 0000 UTC 27 July 2015 forecast indicated 24-h rainfall in excess of $50 \mathrm{~mm}$ between $T+72$ and $48 \mathrm{~h}$. For 1-day lead-time forecasts, the CDF shifted substantially to even higher 


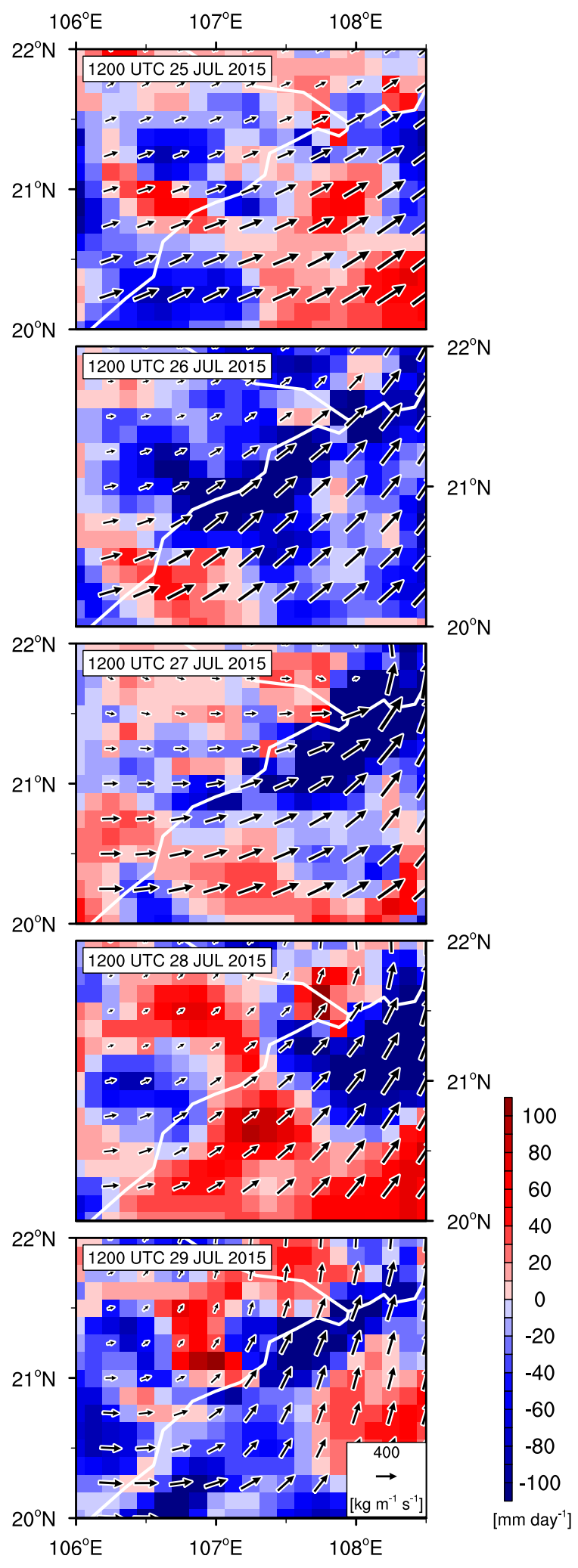

FIG. 10. Surface-300-hPa vertically integrated moisture flux (vectors; $\mathrm{kg} \mathrm{m}^{-1} \mathrm{~s}^{-1}$ ) and moisture flux divergence (contours; mm day $^{-1}$ ) between 1200 UTC 25 Jul and 1200 UTC 29 Jul 2015 (calculations based on ECMWF operational analysis). precipitation amounts, giving a clear indication of an imminent extreme event. For this lead-time forecast, 1 of the 51 ensemble members reaches precipitation amounts of about $290 \mathrm{~mm} \mathrm{day}^{-1}$. This is lower than the amount that was measured in Cua Ong $\left(433 \mathrm{~mm} \mathrm{day}^{-1}\right)$, but higher than the NASA GPM IMERG rainfall amount $\left(106.2 \mathrm{~mm} \mathrm{day}^{-1}\right)$. Thus, this analysis shows that not until 3 days before the event, was an indication of the extreme event evident from ECMWF EPS forecasts.

To gain more spatiotemporally extensive and quantitative information on imminent extreme events, ECMWF calculates and archives two indices, the EFI and SOT (cf. section 2), for various forecast lead times and several surface variables; among them is 24-h total precipitation accumulation. Qualitatively, the EFI for a given lead time can be understood as the area between the red line (CDF of the model climatology) and the thin black lines (CDF of the 51-member ensemble forecasts) in Fig. 11. The EFI used here is normalized, meaning that it ranges between -1 and +1 . A high EFI is indicative of an EPS forecast distribution that is considerably different from the model climatology (Lalaurette 2003), and a value of EFI $=1$ signifies that all members exceed the highest value of the model climatology. Following ECMWF (2015), the weather is likely "unusual" or "very unusual" for EFI values from 0.5 to 0.8 or above 0.8 , respectively. In Fig. 12, EFI values higher than 0.5 are colored. The area between the CDF of the climate and the ensemble forecast can be quite small (in fact, negative values may occur if the forecast CDF is to the left of the model CDF), yet a few members can show extreme daily precipitation values; that is, both curves differ at the tail of the distribution. For the forecaster, this yet signifies a threat of an extreme event. The SOT index has been introduced to quantify this behavior. The index is defined as

$$
\operatorname{SOT}(90)=\frac{Q_{f}(90)-Q_{c}(99)}{Q_{c}(99)-Q_{c}(90)},
$$

where $Q_{c}(90)$ and $Q_{c}(99)$ are the 90th and 99th quantiles of the climatological CDF, whereas $Q_{f}(90)$ is the 90th quantile of the forecast CDF (Hewson 2014). If the SOT index is greater than zero, at least $10 \%$ of the ensemble members exceed the 99th percentile of the model climatology (ECMWF 2016). A pronounced shift of tails is for example evident in Fig. 11 between 72- and 24-h lead times.

As evident from Fig. 12, the EFIs for the 24-h leadtime forecasts indicate extreme 24-h rainfall over northeast Vietnam, the Gulf of Tonkin, and southeastern China for all days between 0000 UTC 26 July and 0000 UTC 29 July 2015. To ensure that protection 


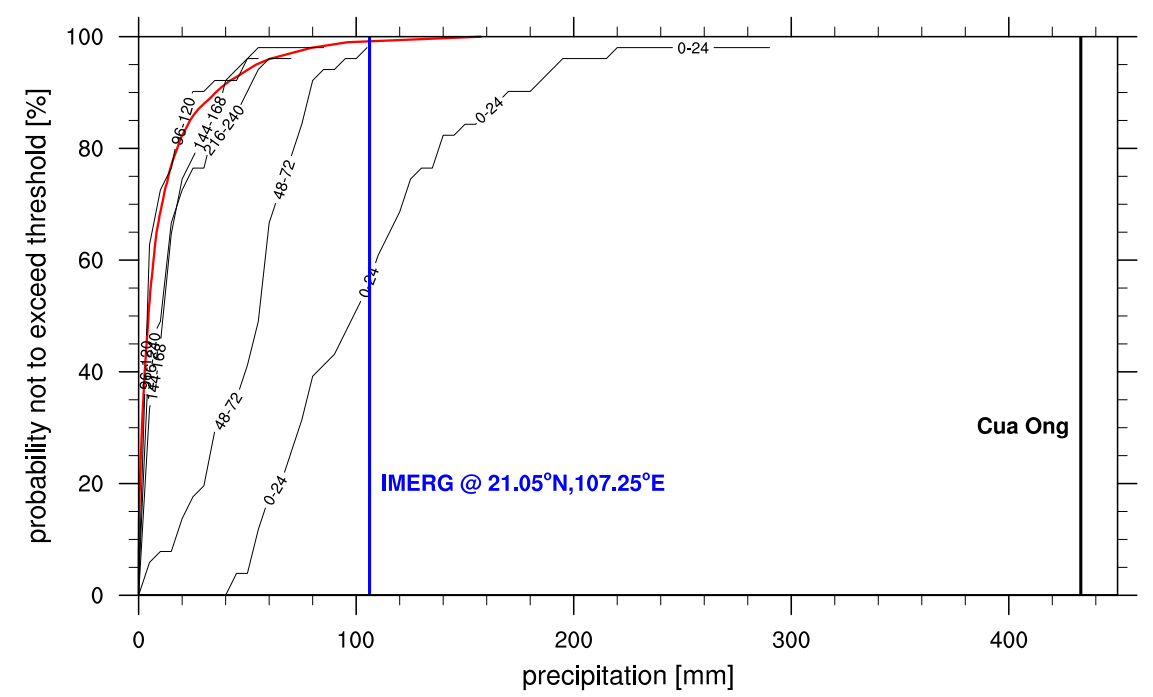

FIG. 11. ECMWF EPS model climatology (red line; 0000 UTC 24 Jul 2015, 24-h lead times) and ensemble statistics for 0000 UTC 27 Jul 2015 with 1-, 3-, 5-, 7-, and 10-day lead times (black lines) at $21^{\circ} \mathrm{N}, 107.25^{\circ} \mathrm{E}$ (cf. Fig. 1). The boldface blue and boldface black lines denote the daily precipitation amounts at the closest NASA GPM IMERG grid box (i.e., $21.05^{\circ} \mathrm{N}$, $107.25^{\circ} \mathrm{E}$ ) and in Cua Ong (cf. Fig. 1), respectively.

measures can be taken and warnings can be issued in a timely fashion, lead times of up to $72 \mathrm{~h}$ are desirable (Jones and Golding 2014). The EFIs are slightly weaker for 72-h lead-time forecasts but still indicate extreme rainfall over the study region (Fig. 12). For the same forecast lead times and for the same region, SOT index values greater than zero from 27 July 2015 onward indicate that extremes at the tail of the EPS distribution, which exceed the 99th percentile of the model climatological CDF, are also present. Note that the forecast lead time, at which a first indication of an event is given, and the intensity of the extreme event in terms of its representation in EFI and SOT do not substantially change for longer than 24-h accumulation periods (not shown).

From a dynamical point of view, it is interesting to understand why the predictability appeared relatively abrupt for about 3-day lead times. The analyses presented in section 4 strongly suggested that the presence of the $200-\mathrm{hPa}$ geopotential height trough, its geographical position, and its axis alignment played an important role in the evolution of this extreme event in northeastern Vietnam. For this reason, the representation of the extreme event in the ensemble forecasts (i.e., the occurrence of extremes with respect to the model climatology) was evaluated in connection with the occurrences and locations of troughs in the ensemble forecasts. For 27 July 2015, the first indication of an extreme event in northeastern Vietnam is given by EFI values greater than 0.5 in the $96-\mathrm{h}$ (4 day) lead-time forecast (Fig. 13). A trough could be detected for most ensemble members at this forecast lead time, but the spread of the locations and tilts of the trough axes is rather large. For forecast lead times greater than $96 \mathrm{~h}$, a significantly decreasing number of ensemble members showed the trough at all, and if so, the spread of the locations of the trough axes further increased; for these forecast lead times, the EFI and SOT index also gave no indication of an extreme event. For the 72-, 48-, and 24-h lead-time forecasts, the EFI and SOT index values increase along with a sharpening of the ensemble forecasts of the trough axes. Sharper and more accurate forecasts of the trough axes went along with less spread in mean sea level pressure contours and thus the depiction of the surface low described in section 4 (cf. Figs. 13 and S5). Interestingly, although the spread of the trough axes is higher for the 72-h lead-time forecast, the EFI and SOT are higher at the Vietnamese coast when compared with the 48-h lead-time forecast (Fig. 13). This could be related to the fact that most members with 48-h lead times locate the trough axes west of the location that was determined with the ECMWF operational analysis. On the contrary, trough axes determined with 72-h lead-time forecasts tend to be centered around the ECMWF operational analysis.

To further strengthen the assumptions concerning the role of the upper-level trough in the extreme event, the trough axes of the ensemble members with the highest and lowest $10 \%$ of area-averaged rainfall $\left(20.5^{\circ}-21.75^{\circ} \mathrm{N}\right.$, $\left.106.75^{\circ}-108.5^{\circ} \mathrm{E}\right)$ were compared. Figure S6 illustrates 


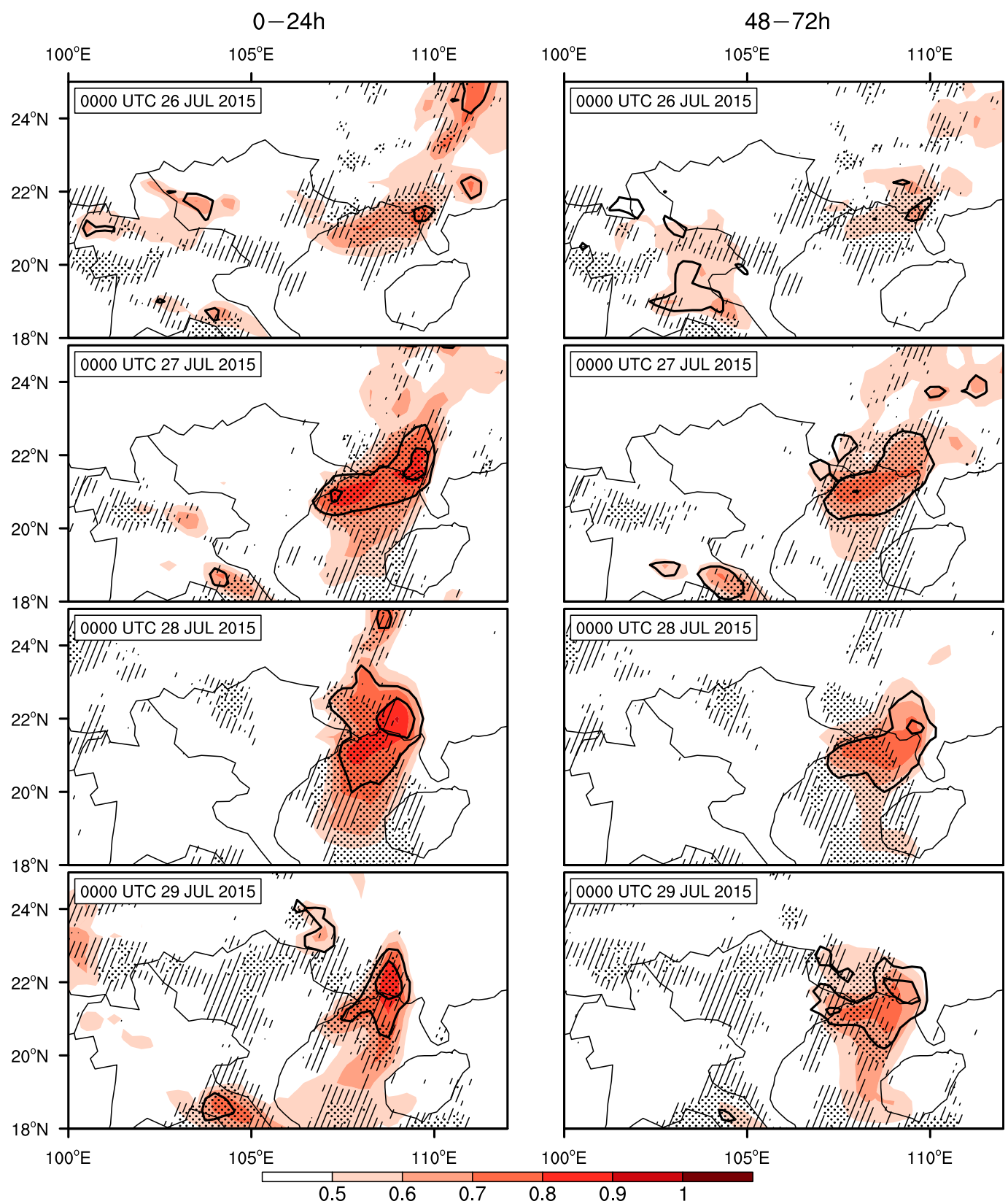

FIG. 12. ECMWF EFI (colors) and SOT index (contours; contour levels 0, 1, and 5) at 0000 UTC 26-29 Jul 2015 for (left) 24- and (right) 72-h lead times. Hatching (stippling) indicates NASA GPM IMERG rainfall amounts above 25 (50) $\mathrm{mm} \mathrm{day}^{-1}$.

that it is mainly the ensemble members that correctly simulate the position and tilt of the upper-level trough that reach the highest forecasted rainfall amounts. This is most evident for lead times of $96 \mathrm{~h}$ or more. In summary, it appears that the position and tilt of the trough axes in individual ensemble members played an important role in the rainfall distribution in the target region. Overall, for all 24-h lead-time ensemble forecasts during the period 26-29 July 2015, the spread of the trough axes was comparable to that on 27 July 2015 (not shown). Moreover, the locations of the trough axes also enclosed the locations of trough axes determined with the ECMWF operational analysis on these days (not shown).

The analysis of the ECMWF ensemble predictions corroborated the notion that the synoptic forcing of the extreme event by the subtropical trough and associated surface low was instrumental. About 3 days before the 

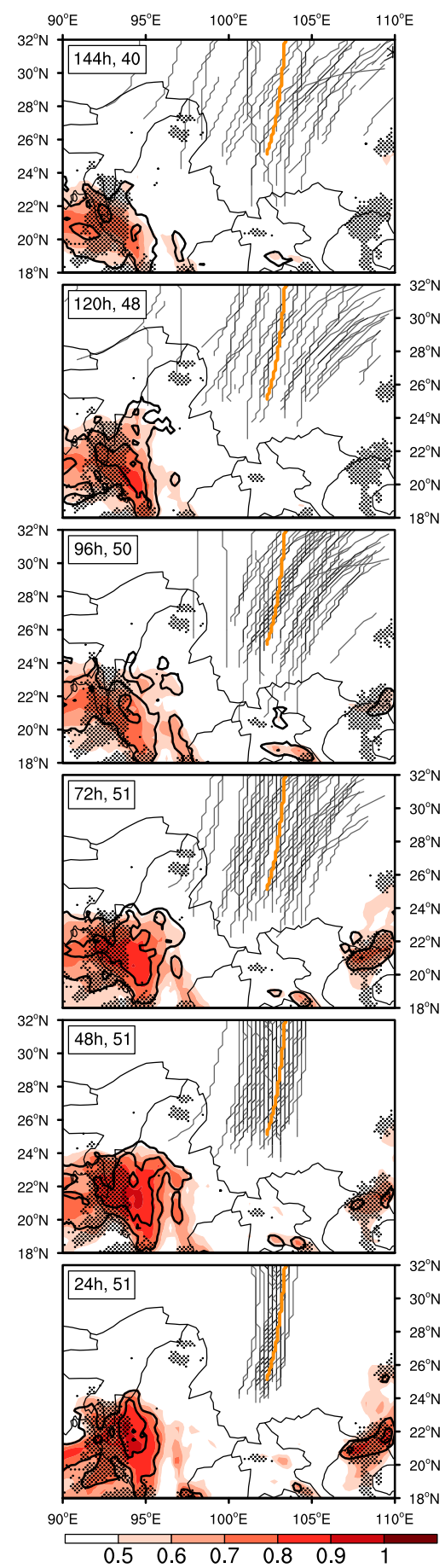

FIG. 13. ECMWF EFI (colors), SOT index (black contours; contour levels 0, 1, and 5), ECMWF EPS 200-hPa geopotential height trough axes (gray lines), and ECMWF operational analysis 200-hPa geopotential height trough axis (orange line) at 0000 UTC $27 \mathrm{Jul} 2015$ and for (from top to bottom) 144-, 120-, 96-, 72-, 48-, and 24-h lead times. In the case of EFI and SOT, the hours indicate the end of the 24-h period over which the forecasted rainfall for the construction of the two indices was accumulated. The numbers after the lead times in the inset boxes denote the numbers of the 51 ensemble members for which a trough axis was analyzed. Stippling indicates NASA GPM IMERG rainfall amounts above $50 \mathrm{~mm} \mathrm{day}^{-1}$. event, most members forecasted the trough axis in the correct position, and it was not until then when the predictability of the 24-h rainfall totals swiftly emerged from the climatological predictability. In general, the ensemble predictability of 24-h rainfall totals for a given station or grid point barely increases compared with climatology in many parts of the tropics because of the stochastic nature of convection. The Quang Ninh extreme event is a salient example of a case where if a strong synoptic forcing is present, the predictability of convection can suddenly appear once the synoptic forcing processes are well forecasted.

\section{Summary and discussion}

Record-breaking precipitation amounts were observed along the northeastern coast of Vietnam in late July-early August 2015. Rainfall amounts of up to $1500 \mathrm{~mm}$ were measured at coastal stations in Quang Ninh Province during the 9-day period from 1200 UTC 25 July until 1200 UTC 3 August 2015. The event led to flooding, landslides, damage to infrastructure, and loss of life. The observed rainfall amounts were up to 4 times the climatological maxima during this period. Up to $74 \%$ of the total precipitation measured for the whole period was observed at the coast during the four-day period from 1200 UTC 25 July until 1200 UTC 29 July 2015. The present study focused on this first period, when the regions of peak rainfall were mainly limited to the northeastern coast of Vietnam, the Gulf of Tonkin, and southeastern China.

Rainfall during the first period was associated with a surface low over the Gulf of Tonkin and northern Vietnam, in which deep convection was continuously triggered by synoptic-scale tropospheric moisture flux convergence. The formation of the low and its temporal displacement was linked with a 200-hPa geopotential subtropical trough, whose axis was located northwest of Vietnam over southern China and which moved westward and weakened until it was no longer detectable after the first period. Associated with the retrograde displacement of the trough, the onshore component of the tropospheric moisture flux intensified. Outflow from a strong and persistent monsoon depression over the Bay of Bengal, which was upgraded to a tropical storm on 30 July 2015 and which caused disastrous rainfall over Myanmar, was the main moisture source of the extreme event in northeastern Vietnam, but this outflow did not initiate this event. Singh et al. (2001) found that monsoon depressions form more frequently and farther north in the Bay of Bengal during El Niño years. Therefore, the strong 2015/16 El Niño, which was still developing in July-August 2015, might have been a 
factor in the strong moisture transport that was observed. The Madden-Julian oscillation (e.g., Madden and Julian 1972) and convectively coupled equatorial waves (e.g., Kiladis et al. 2009) that are known to modulate rainfall in different parts of Vietnam during the rainy season (e.g., Yokoi et al. 2007; Lubis and Jacobi 2015; van der Linden et al. 2016b) did not indicate an influence on convective activity during this event (not shown).

Reliable forecasts of extreme events in this region, which is highly dependent on revenues from coal production and tourism, are crucial for issuing flood watches and for taking precautionary measures in sufficient time ahead of the event. The EFI and SOT indices gave an indication of an imminent extreme event about 3 days in advance. It was found that the presence and correct axis location of the $200-\mathrm{hPa}$ subtropical geopotential trough and the associated surface low in probabilistic forecasts were the most important factors affecting the predictability of heavy rainfall in northeastern Vietnam. In parallel to the improved predictability of these synoptic forcings, the practical predictability of the extreme rainfall event improved too.

Thus, the major findings of this research can be summarized as follows:

- A slowly moving subtropical trough and associated surface low in the northern Gulf of Tonkin promoted steady moisture convergence and long-lasting convection over northeastern Vietnam.

- The moisture stemmed from a moisture transport band across the Indochina Peninsula that originated from a tropical storm in the Bay of Bengal, but the abovementioned tropical-extratropical interaction caused moisture convergence and rainfall.

- Analyses of the ensemble forecasts clearly showed a sudden emergence of the predictability of the extreme event at lead times of 3 days in association with the correct intensity and location of the subtropical trough in the forecasts.

To the best of the authors' knowledge, such a tropicalextratropical interaction for this region and season has not been documented before. It is a salient example that the low predictability of tropical monsoonal convection is enhanced by the presence of an extratropical synoptic forcing. Thus, it is a suitable contribution to the recently launched WMO High Impact Weather within the World Weather Research Programme (HIWeather) initiative under the research theme "Predictability and Processes" (Jones and Golding 2014). However, in terms of predictability, our investigation should be complemented by the investigation of a multimodel ensemble forecast for the present and other cases to shed light on the question on how often such a tropical-extratropical interaction enhances convective-scale predictability.

For West African winter monsoon rainfall, such an enhancement of predictability has been shown to extend to almost 1 week (Davis et al. 2013). In addition, Söhne et al. (2008) have shown that cloud forecasts during the West African summer monsoon increased when a synoptic forcing from an African easterly wave is present. Currently, a major research initiative is ongoing that tries to better exploit the predictability of West African monsoon dry and wet spells when an extratropical Rossby wave train induces interactions with the Saharan heat low and the West African monsoon (http:// wavestoweather.de). Within this context, the present case study opens avenues of further research to determine the frequency of such tropical-extratropical interactions and their impact on the predictability of monsoon rains for the northern Indochina Peninsula and southern China.

Acknowledgments. The first three authors acknowledge support by the EWATEC-COAST project, which is supported by the Bundesministerium für Bildung und Forschung of Germany (BMBF) Grant 02WCL1217C and by the Vietnam National University of Ho Chi Minh City (VNU-HCM) Grant NDT2012-24-01/HD-KHCN. AHF acknowledges partial support from the subproject "C2 - Prediction of wet and dry periods of the West African monsoon" of the Transregional Collaborative Research Center SFB/TRR 165 "Waves to Weather" funded by the German Science Foundation (DFG). JGP thanks the AXA Research Fund for support. TPV acknowledges support for his research from NAFOSTED Project 105.06-2014.44. We also wish to thank Mr. Le Thanh Hai, Mr. Nguyen Quang Ha, and Mrs. Phan Nhu Quynh from NHMS, who have provided station observations and radar data used in this study. ECMWF products were downloaded from the ECMWF data servers (http://apps.ecmwf.int/datasets/; batch access). We thank the editor and the three anonymous reviewers for their comments that helped to substantially improve the manuscript.

\section{REFERENCES}

American Meteorological Society, 2016: Mei-yu front. Glossary of Meteorology. [Available online at http://glossary.ametsoc.org/ wiki/Mei-yu_front.]

Chen, T.-C., J.-D. Tsay, M.-C. Yen, and J. Matsumoto, 2012: Interannual variation of the late fall rainfall in central Vietnam. J. Climate, 25, 392-413, doi:10.1175/JCLI-D-11-00068.1.

Davis, J., P. Knippertz, and A. H. Fink, 2013: The predictability of precipitation episodes during the West African dry season. 
Quart. J. Roy. Meteor. Soc., 139, 1047-1058, doi:10.1002/ qj.2014.

Dee, D. P., and Coauthors, 2011: The ERA-Interim reanalysis: Configuration and performance of the data assimilation system. Quart. J. Roy. Meteor. Soc., 137, 553-597, doi:10.1002/ qj. 828 .

Du Duc, T., L. R. Hole, D. Tran Anh, C. Hoang Duc, and T. Nguyen Ba, 2016: Verification of forecast weather surface variables over Vietnam using the National Numerical Weather Prediction System. Adv. Meteor., 2016, 8152413, doi:10.1155/2016/8152413.

Durre, I., R. S. Vose, and D. B. Wuertz, 2006: Overview of the Integrated Global Radiosonde Archive. J. Climate, 19, 53-68, doi:10.1175/JCLI3594.1.

ECMWF, 2015: User guide to ECMWF forecast products. 129 pp. [Available online at http://www.ecmwf.int/sites/default/files/ User_Guide_V1.2_20151123.pdf.]

_ 2016: Medium Range Forecasts: Severe weather - The Extreme Forecast Index. [Available online at http://www.ecmwf. int/en/forecasts/documentation-and-support/medium-rangeforecasts.]

Fröhlich, L., and P. Knippertz, 2008: Identification and global climatology of upper-level troughs at low latitudes. Meteor. Z., 17, 565-573, doi:10.1127/0941-2948/2008/0320.

Guo, H., S. Chen, A. Bao, A. Behrangi, Y. Hong, F. Ndayisaba, J. $\mathrm{Hu}$, and P. M. Stepanian, 2016: Early assessment of integrated multi-satellite retrievals for global precipitation measurement over China. Atmos. Res., 176-177, 121-133, doi:10.1016/j.atmosres.2016.02.020.

Hewson, T., 2014: Severe weather prediction at ECMWF-Recent developments and future challenges. World Meteorological Organization, 57 pp. [Available online at https://www.wmo. int/pages/prog/arep/wwrp/new/wwosc/documents/WWOSC2014_ Hewson_SevereWeatherECMWF.pdf.]

Huffman, G. J., and Coauthors, 2007: The TRMM Multisatellite Precipitation Analysis (TMPA): Quasi-global, multiyear, combined-sensor precipitation estimates at fine scales. J. Hydrometeor., 8, 38-55, doi:10.1175/JHM560.1.

—, D. T. Bolvin, D. Braithwaite, K. Hsu, R. Joyce, C. Kidd, E. J. Nelkin, and P. Xie, 2015: Algorithm Theoretical Basis Document (ATBD) version 4.5. NASA Global Precipitation Measurement (GPM) Integrated Multi-satellite Retrievals for GPM (IMERG), 30 pp.

Jiang, H., and E. J. Zipser, 2010: Contribution of tropical cyclones to the global precipitation from eight seasons of TRMM data: Regional, seasonal, and interannual variations. J. Climate, 23, 1526-1543, doi:10.1175/2009JCLI3303.1.

Jones, S., and B. Golding, 2014: HIWeather: A research activity on High Impact Weather within the World Weather Research Programme. Implementation Plan, WWRP, 87 pp. [Available online at http://www.wmo.int/pages/prog/arep/wwrp/new/ documents/HIW_IP_v1_4.pdf.]

Kiladis, G. N., M. C. Wheeler, P. T. Haertel, K. H. Straub, and P. E. Roundy, 2009: Convectively coupled equatorial waves. Rev. Geophys., 47, RG2003, doi:10.1029/2008RG000266.

Knippertz, P., 2004: A simple identification scheme for upper-level troughs and its application to winter precipitation variability in northwest Africa. J. Climate, 17, 1411-1418, doi:10.1175/ 1520-0442(2004)017<1411:ASISFU>2.0.CO;2.

Lafore, J.-P., and Coauthors, 2017: Deep convection. Meteorology of Tropical West Africa: The Forecasters' Handbook, D. J. Parker and M. Diop-Kane, Eds., John Wiley and Sons, doi:10.1002/9781118391297.ch3.
Lalaurette, F., 2003: Early detection of abnormal weather conditions using a probabilistic extreme forecast index. Quart. J. Roy. Meteor. Soc., 129, 3037-3057, doi:10.1256/qj.02.152.

Li, S., and A. W. Robertson, 2015: Evaluation of submonthly precipitation forecast skill from global ensemble prediction systems. Mon. Wea. Rev., 143, 2871-2889, doi:10.1175/ MWR-D-14-00277.1.

Lubis, S. W., and C. Jacobi, 2015: The modulating influence of convectively coupled equatorial waves (CCEWs) on the variability of tropical precipitation. Int. J. Climatol., 35, 14651483, doi:10.1002/joc.4069.

Madden, R. A., and P. R. Julian, 1972: Description of global-scale circulation cells in the tropics with a 40-50 day period. J. Atmos. Sci., 29, 1109-1123, doi:10.1175/1520-0469(1972)029<1109: DOGSCC $>2.0 . \mathrm{CO} ; 2$.

Milton, S., A. Diongue-Niang, B. Lamptey, C. Bain, and C. Birch, 2017: Numerical weather prediction over Africa. Meteorology of Tropical West Africa: The Forecasters' Handbook, D. J. Parker and M. Diop-Kane, Eds., John Wiley and Sons, doi:10.1002/9781118391297.ch10.

Nguyen, D.-Q., J. Renwick, and J. McGregor, 2014: Variations of surface temperature and rainfall in Vietnam from 1971 to 2010. Int. J. Climatol., 34, 249-264, doi:10.1002/joc.3684.

Nguyen, K. C., J. J. Katzfey, and J. L. McGregor, 2014: Downscaling over Vietnam using the stretched-grid CCAM: Verification of the mean and interannual variability of rainfall. Climate Dyn., 43, 861-879, doi:10.1007/s00382-013-1976-5.

Nguyen-Thi, H. A., J. Matsumoto, T. Ngo-Duc, and N. Endo, 2012: A climatological study of tropical cyclone rainfall in Vietnam. SOLA, 8, 41-44.

Peixoto, J. P., and A. H. Oort, 1992: Physics of Climate. American Institute of Physics, $520 \mathrm{pp}$.

Phan, V.-T., T. Ngo-Duc, and T.-M.-H. Ho, 2009: Seasonal and interannual variations of surface climate elements over Vietnam. Climate Res., 40, 49-60, doi:10.3354/cr00824.

Prakash, S., and A. K. Mitra, A. AghaKouchak, Z. Liu, H. Norouzi, and D. S. Pai, 2017: A preliminary assessment of GPM-based multi-satellite precipitation estimates over a monsoon dominated region. J. Hydrol., doi:10.1016/j.jhydrol.2016.01.029, in press.

Reynolds, R. W., T. M. Smith, C. Liu, D. B. Chelton, K. S. Casey, and M. G. Schlax, 2007: Daily high-resolution-blended analyses for sea surface temperature. J. Climate, 20, 5473-5496, doi:10.1175/2007JCLI1824.1.

Singh, O. P., T. M. Ali Khan, and M. S. Rahman, 2001: Probable reasons for enhanced cyclogenesis in the Bay of Bengal during July-August of ENSO years. Global Planet. Change, 29, 135147, doi:10.1016/S0921-8181(00)00090-4.

Söhne, N., J.-P. Chaboureau, and F. Guichard, 2008: Verification of cloud cover forecast with satellite observation over West Africa. Mon. Wea. Rev., 136, 4421-4434, doi:10.1175/ 2008MWR2432.1.

United Nations, 2015: Vietnam: Heavy rainfall and flooding in northern Viet Nam. Vietnam Emergency Situation Rep. 3, United Nations, 17 pp. [Available online at http://reliefweb. int/report/viet-nam/vietnam-heavy-rainfall-and-flooding-northernviet-nam-situation-report-no3-7-august.]

Van der Linden, R., A. H. Fink, T. Phan-Van, and L. Trinh-Tuan, 2016a: Synoptic-dynamic analysis of early dry-season rainfall events in the Vietnamese central highlands. Mon. Wea. Rev., 144, 1509-1527, doi:10.1175/MWR-D-15-0265.1.

, , J. G. Pinto, T. Phan-Van, and G. N. Kiladis, 2016b: Modulation of daily rainfall in southern Vietnam by the 
Madden-Julian oscillation and convectively coupled equatorial waves. J. Climate, 29, 5801-5820, doi:10.1175/ JCLI-D-15-0911.1.

Webster, P. J., and Coauthors, 2010: Extended-range probabilistic forecasts of Ganges and Brahmaputra floods in Bangladesh. Bull. Amer. Meteor. Soc., 91, 1493-1514, doi:10.1175/ 2010BAMS2911.1.

WMO, 2015: Special tropical weather outlooks and tropical cyclone advisory bulletins. Regional Specialized Meteorological Centre, New Delhi, India, 26 pp. [Available online at http:// www.rsmcnewdelhi.imd.gov.in/images/pdf/archive/bulletins/ 2015/RKO.pdf.]

Wu, P., Y. Fukutomi, and J. Matsumoto, 2011: An observational study of the extremely heavy rain event in northern Vietnam during 30 October-1 November 2008. J. Meteor. Soc. Japan, 89A, 331-344, doi:10.2151/jmsj.2011-A23.

, and - 2012: The impact of intraseasonal oscillations in the tropical atmosphere on the formation of extreme central Vietnam precipitation. SOLA, 8, 57-60.

$\mathrm{Xu}$, W., E. J. Zipser, and C. Liu, 2009: Rainfall characteristics and convective properties of mei-yu precipitation systems over South China, Taiwan, and the South China Sea. Part I: TRMM observations. Mon. Wea. Rev., 137, 4261-4275, doi:10.1175/ 2009MWR2982.1.

Yanase, W., M. Satoh, H. Taniguchi, and H. Fujinami, 2012: Seasonal and intraseasonal modulation of tropical cyclogenesis environment over the Bay of Bengal during the extended summer monsoon. J. Climate, 25, 2914-2930, doi:10.1175/ JCLI-D-11-00208.1.

Yihui, D., and J. C. L. Chan, 2005: The East Asian summer monsoon: An overview. Meteor. Atmos. Phys., 89, 117-142, doi:10.1007/s00703-005-0125-z.

Yokoi, S., and J. Matsumoto, 2008: Collaborative effects of cold surge and tropical depression-type disturbance on heavy rainfall in central Vietnam. Mon. Wea. Rev., 136, 3275-3287, doi:10.1175/2008MWR2456.1.

_ , T. Satomura, and J. Matsumoto, 2007: Climatological characteristics of the intraseasonal variation of precipitation over the Indochina Peninsula. J. Climate, 20, 5301-5315, doi:10.1175/2007JCLI1357.1.

Zsótér, E., 2006: Recent developments in extreme weather forecasting. ECMWF Newsletter, No. 107, ECMWF, Reading, United Kingdom, 8-17. [Available online at http://www. ecmwf.int/en/elibrary/14618-newsletter-no107-spring-2006.] 